\title{
Removal of Cr from synthetic wastewater by sorption into volcanic ash soil
}

\author{
*S. Babel, E. M. Opiso
}

Environmental Technology Program, School of Bio-Chemical Engineering and Technology, Sirindhorn International Institute of Technology, Thammasat University, Pathumthani, Thailand

Received 16 November 2006; revised 27 November 2006; accepted 5 December 2006; available online 1 January 2007

\begin{abstract}
The possibility of using volcanic ash soils (VAS) or Andisols as a low-cost and natural adsorbent is investigated in this study for the removal of $\mathrm{Cr}$ (VI) from synthetic wastewater. Andisols can be used as adsorbent because they are characterized by the presence of non-crystalline secondary minerals such as allophane and imogolite that show variable charge characteristics and have the ability to retain cations and anions. The adsorption of $\mathrm{Cr}$ on to two VAS from Mt. Isarog and Mandalagan (B-Horizon), Philippines, was carried out at ambient temperature using batch adsorption studies. The effects of different parameters such as amount of adsorbent, contact time, initial $\mathrm{Cr}$ concentration and $\mathrm{pH}$ of the solution were investigated. The results showed that the VAS from Isarog is more effective in the removal of $\mathrm{Cr}$ than in Mandalagan. The maximum removal efficiency of the Isarog soil for a $\mathrm{Cr}$ concentration of $10 \mathrm{mg} / \mathrm{L}$ reached $89 \%$ with a dose of $20 \mathrm{~g} / \mathrm{L}$ at a moderately acidic $\mathrm{pH}$ of 3 . The Mandalagan soil on the other hand could remove only $65 \%$ at the same $\mathrm{pH}$ conditions and parameters. The difference in the removal of the two soils may be attributed to their physico-chemical properties in which the Isarog soil has higher clay content, porosity and lower bulk density. Isarog soil has fine particles with higher surface area and more active noncrystalline minerals and thus has higher removal efficiency than Mandalagan soil. Based on the results, the use of VAS from Isarog appears to be economical and an alternative to commercially available adsorbents for the removal of $\mathrm{Cr}$ from contaminated wastewater.
\end{abstract}

Key words: Adsorption, volcanic ash soil, andisols, chromium, adsorption isotherm

\section{INTRODUCTION}

The removal of $\mathrm{Cr}$ from contaminated wastewater is necessary because of its high toxicity to living organisms. It is both a mutagen and carcinogen at low sub-ppm levels (Stewart, et al., 2003). It is highly soluble in aquatic environment and can be readily adsorbed by living organisms. Once it accumulates in living organisms beyond the allowable concentration, it can cause severe health problems (Kurniawan, 2002). Prolonged exposure to even small concentrations can cause lung cancer, liver and kidney damage and reproductive problems (Terry, 2004). The cationic trivalent chromium on the other hand is an important mineral supplement and it is less mobile compared to Cr (Stepniewska, et al., 2004). Several technologies have been developed for the removal of chromium in aqueous solutions over the years. The most significant of these techniques include chemical precipitation,

*Corresponding author, Email: sandhya@siit.tu.ac.th

Tel.: +66-2 9869009 (ext.2307); Fax: +66-2 986-9009 ext 2301 filtration, reverse osmosis, ion exchange by resin, and membrane systems. The major drawbacks from these technologies include incomplete removal, high reagent and energy requirement, generation of toxic sludge, and high operational cost (Esmaili, et al., 2003). In recent years, adsorption has been shown to be an alternative method for removing dissolved metal ions from liquid waste. In order to minimize the cost, extensive research using low-cost adsorbents including various kinds of soils and clay materials has been carried out in several investigations (Potgeiter, et al., 2005, Okada, et al., 2005). Cationic heavy metal retention in soils is due to its strong adsorption onto the negatively charged soil surfaces, the ability to form complex molecules with organics found in the soil and the formation of oxides, hydroxides and other insoluble minerals in soil (Stewart, et al., 2003). Several kinds of crystalline clay minerals such as zeolites, kaolinite and montmorillonite also appear to be suitable for the removal of heavy metal 
cations. Such efficiency of clays is a result of their chemical and mechanical stability, high surface area, permanent negative charge and a variety of surface and structural properties (Krishna, et al., 2000). From the experimental studies on Cr by Fendorf, (1994), it was concluded that $\mathrm{Cr}$ is appreciably retained in soil colloids with net positive charge due to its anionic nature and is adsorbed by a variety of soil phases with hydroxyl groups on their surfaces such as those present in kaolinite and montmorillonite (Bradl, 2004). Competitive ion displacement studies in soil have also shown that $\mathrm{Cr}$ is retained much more strongly than anions such as $\mathrm{Cl}^{-}$and $\mathrm{SO}_{4}{ }^{2-}$ and that its retention strength approaches that of phosphate (Fendorf, 1994). Moreover, anions, particularly $\mathrm{PO}_{4}$ and $\mathrm{AsO}_{4}$ are specifically adsorbed in soil mainly on variable charge minerals ( $\mathrm{pH}$-dependent charge) such as allophane and imogolite. Soils like Andisols (volcanic ash soil) are dominated in its colloidal fraction by these variable charge soil minerals that could adsorb up to more than $1000 \mathrm{mmol} / \mathrm{kg}$ of $\mathrm{PO}_{4}$ and $\mathrm{AsO}_{4}$ depending upon the amount of these minerals as reported in the study of Violante, et al., (2002). Andisols can also adsorb large amounts of other anions such as sulfate, molybdate and fluoride (Zevenbergen, et al., 1996). Hence, research on the application of volcanic ash soil as an alternative low cost adsorbent for the removal of $\mathrm{Cr}$ in contaminated wastewater is very important. In this paper, the possibility of using volcanic ash soils (VAS) to remove $\mathrm{Cr}$ from aqueous solution was investigated using batch adsorption studies. The properties of VAS and surface functional groups were also studied in order to understand the adsorption mechanism and efficiencies of the two soils. The effect of various factors such as initial $\mathrm{pH}$ and amount of adsorbent on the removal efficiency of VAS were also studied. The data on adsorption isotherms were also presented using Langmuir and Freundlich models to describe the adsorption kinetics. The major research was carried out in the Environmental Technology Laboratory of Sirindhorn International Institute of Technology, Thammasat University, Pathumthani, Thailand. Some of the analysis was done in the Faculty of Science Laboratory, Thammasat University. The soil samples were collected from Mt. Isarog, Camarines Sur and Mt. Mandalagan, Negros Occidental in the Philippines. The research of this paper was carried out from March to October 2006.

\section{MATERIALS AND METHODS}

Preparation and characterization of adsorbents

The two kinds of volcanic ash soil (VAS) used in this study were obtained from the Philippines at the foot slopes of Mt. Isarog, Camarines Sur and Mt. Mandalagan, Negros Occidental. The soil samples were taken in the B-horizon and were kept in the field-moist state to prevent possible irreversible changes upon drying. The soil samples were air-dried before the experiment and were crushed to pass a $2 \mathrm{~mm}$ sieve. Only the clay fraction passing less than the $2 \mathrm{~mm}$ sieve was used as adsorbent for the study. The physical and chemical properties of the soil samples were also determined. The soil $\mathrm{pH}$ by $\mathrm{NaF}$ was determined by Blackmore method; organic carbon content was determined by the Walkley and Black method; organic matter was determined by multiplying Van Bemmelen Factor to organic carbon, bulk density was obtained by paraffin clod method, porosity was determined by water saturation method (Smith, et al, 1976). Clay mineralogy and the different surface functional groups were analysed using XRD-analysis and FTIR spectroscopy, respectively.

\section{Instrumentation}

A CECIL/CE model 1021 series spectrophotometer was employed to measure the residual metal ion concentration by colorimetric method. The $\mathrm{pH}$ of the solutions was measured using a $\mathrm{pH}$ meter with glass electrode. A mechanical shaker model Sseriker II PNP was used for shaking the different adsorption batches. The treated sample was centrifuged using NUVE model NF 800. GF/C filter was used to separate the soil from the solution after centrifugation. An analytical balance model Metler Toledo (PB 602-S) was used for weighing the soil and other chemicals. The clay minerals were analysed by using a Bruker AXS GMBH X-Ray Powder Diffractometer. The FTIR Elmer-Perkins Systems 2000 model was used to determine the different surface functional groups responsible for the retention of $\mathrm{Cr}$.

\section{Experimental procedure}

Stock solution of $500 \mathrm{mg} / \mathrm{L}$ of $\mathrm{Cr}$ as a source of synthetic wastewater was prepared by dissolving $0.7071 \mathrm{~g}$ of analytical reagent grade of $\mathrm{K}_{2} \mathrm{Cr}_{2} \mathrm{O}_{7}$ in 500 $\mathrm{mL}$ deionised water. Three different $\mathrm{Cr}$ concentrations of 5,10 and $25 \mathrm{mg} / \mathrm{L}$ were prepared by diluting appropriate amounts from the stock solution. The adsorption studies were conducted using a batch 
technique at ambient temperature. Suitable amounts of soil sample were placed in different Erlenmeyer flasks of $250 \mathrm{~mL}$ capacity containing $50 \mathrm{~mL}$ of $\mathrm{Cr}$ metal solution of known concentration and $\mathrm{pH}$. The experiments were carried out at original $\mathrm{pH}$ of the solution except when the effect of $\mathrm{pH}$ and contact time were studied. The $\mathrm{pH}$ of the solution was adjusted to the desired value by adding dilute $\mathrm{HCl}$ or $\mathrm{NaOH}$ solutions. The solutions were shaken at $150 \mathrm{rpm}$ for 3 $h$ except when the effect of contact time was investigated. At the end of the shaking period, the suspensions were centrifuged at $4000 \mathrm{rpm}$ for 20 minutes and were then filtered using GF/C. The $\mathrm{Cr}$ concentration of the supernatant in each flask was analysed by colorimetric method using a spectrophotometer at $540 \mathrm{~nm}$. The soil used as adsorbent after the treatment was analysed by IRspectroscopy to understand the mechanism of adsorption of $\mathrm{Cr}$. The contact time was varied from 1$12 \mathrm{~h}$, the dose of adsorbent from 10 to $60 \mathrm{~g} / \mathrm{L}$ and the $\mathrm{pH}$ from 2-7.

\section{Adsorption isotherms}

In this study, the adsorption isotherms were determined for the two volcanic ash soils. Soil suspensions of 5 to $25 \mathrm{~g} / \mathrm{L}$ in $50 \mathrm{~mL}$ of $10 \mathrm{mg} / \mathrm{L} \mathrm{Cr}$ solution were shaken at ambient temperature at optimum $\mathrm{pH}$ and contact time. The suspensions were centrifuged and the residual $\mathrm{Cr}$ was determined from the filtered supernatant solution using a spectrophotometer and the amount of $\mathrm{Cr}$ adsorbed was calculated. The sorption data have been correlated with suitable isotherm. Langmuir and Freundlich isotherm models were fitted to the adsorption data and their constants were determined and evaluated. The conformity of the model with the experimental data was expressed by the correlation coefficient $\left(\mathrm{R}^{2}\right)$.

Table 1: Physico-chemical properties of studied soils

\begin{tabular}{lll}
\hline Properties & Mt. Isarog & Mt. Mandalagan \\
\hline Color & & \\
A-Horizon & Black & Brown \\
B-Horizon & Dark Brown & Yellow Brown \\
Texture & Loam & Sand \\
Clay (\%) & 44.2 & 5 \\
Bulk Density (g/cc) & 0.64 & 0.978 \\
Porosity (\%) & 75.84 & 52.74 \\
pH (NaF) & 9.5 & 11.28 \\
Organic C (\%) & 2.82 & 2.47 \\
Organic Matter (\%) & 4.85 & 4.25 \\
\hline
\end{tabular}

\section{RESULTS}

\section{Adsorbent characterization}

The two volcanic ash soils used as an adsorbent for $\mathrm{Cr}$ in this study are classified as Hydric Melanudand for Isarog and Vitric Hapludand for Mandalagan based on the criteria of the International Committee in the Classification of Andisols (ICOMAND) (Otsuka, et al., 1988). These soils are commonly called Andisols and are one of the major soil orders in the soil taxonomy. Andisols mainly result from the fast weathering of fine basaltic, andesitic or trachytic ashes, and recent pyroclastic deposits through hydrolysis of volcanic glass and make complex compounds with organic acids. The B-horizons typically are loamy and puffy due to low density and to high allophane and water content, and they still contain a considerable amount of humus ( 1 to $5 \%$ organic matter) despite their light color. In the field, B-horizons appear massive, without aggregates, but rich in microporosity (Perret, et al., 1999). The physicochemical properties of the studied volcanic ash soils which confirmed their typical characteristics are shown in Table 1. It can be seen that the accumulation of organic matter in Isarog is more prevalent than in Mandalagan based on the color difference between the A-horizon of the two soils in which the color of the former is black compared to brown of the latter. The reason for high humus accumulation is stabilization of humus by complexation with $\mathrm{Al}$ (Nanzyo, 2002). The two soils also differ in their bulk density in which the Isarog soil is much lighter and much more porous. Moreover, the higher value of the percentage amount of clay in Isarog may confirm that a higher degree of weathering processes occurred compared to the other soil. Based on these observations, it can be said that the volcanic ash soil from Isarog may contain more amorphous secondary minerals and non-crystalline mineral humus complexes in their colloidal fractions as compared to Mandalagan. The higher value of $\mathrm{pH}(\mathrm{NaF})$ which is greater than 8 of the two VAS, also indicates that the samples contain large amounts of allophane.

\section{Clay mineralogy and surface functional groups}

The secondary clay minerals of volcanic ash soil, particularly Andisols are dominated by short-ranged order minerals (non-crystalline minerals). Among the most common are allophane and imogolite and they show variable charged characteristics, high phosphate retention capacity and high affinity for multi-valent cations (Nanzyo, 2002). 
These amorphous minerals on the other hand cannot be easily detected by XRD. The XRD-analysis revealed that most of the peaks observed matched with $\mathrm{SiO}_{2}$ or $\mathrm{H}_{2} \mathrm{SO}_{4}$ and $\mathrm{CaSiOH}$. These compounds can be associated with the primary minerals such as quartz and feldspar.In addition, the peak for $\mathrm{COOH}$ was also observed from the Isarog soil samples confirming its high organic matter content.However, the study of Otsuka, et al., (1988) of the volcanic ash soil in Mt Isarog and Mt. Mandalagan tested positive in the allophane test. Xray Diffractogram of their clays treated with $\mathrm{Mg}++, \mathrm{K}+$ and glycerol also showed broad peaks that corresponded to imogolite. Similar findings were also observed by FTIR analysis which shows the bands of $\mathrm{SiO}_{2}$. The spectra of the two soils also showed two bands around 3400 and 1600 which can be attributed to the existence of surface hydroxyl groups and adsorbed moisture. It also showed the bands of the carbonates groups. This interpretation of the XRD and FTIR analysis is in good agreement with the physico-chemical properties described in Table 1 which confirmed that two VAS are dominated by amorphous minerals in its colloidal fraction.

\section{Adsorption Studies}

Effect of dose of adsorbent and initial $\mathrm{Cr}$ concentration

The effect of the amount of volcanic ash soil on the removal of $\mathrm{Cr}$ from synthetic wastewater is shown in
Fig. 1. The results showed that the $\mathrm{Cr}$ removal percentage increases as the dose of the volcanic ash soil also increases. Similar adsorption behaviour of $\mathrm{Cr}$ was observed by Potgeiter et al., (2005) when using palygorskite clay as an adsorbent. This increasing trend is expected since the number of adsorption sites also increases. The percentage removal by the Isarog soil is higher compared to Mandalagan by around 20\% at the same dose and $\mathrm{Cr}$ concentration. The maximum removal efficiency of the two soils for $10 \mathrm{mg} / \mathrm{L}$ of $\mathrm{Cr}$ and soil dose of $60 \mathrm{~g} / \mathrm{L}$ reached $93 \%$ for Isarog as compared to $71 \%$ for Mandalagan. The difference in the adsorption performance of the two soils is expected because of the difference in their properties. These results may prove that the Isarog soils contain much more amorphous soil minerals which have higher capacity to bind Cr compared to Mandalagan. The slight increase in the removal efficiency as the amount of adsorbent increases from 40 to $60 \mathrm{~g} / \mathrm{L}$ indicates that the saturation point is nearly reached. On the other hand, experiments done with $5 \mathrm{mg} / \mathrm{L} \mathrm{Cr}$ concentration resulted in a slight increase in removal (76 \%) for the same dose of adsorbent (60 g/L) for Mandalagan soil. It was also found that for the Isarog soil, the maximum removal efficiency at the same dose of soil decreases by $10 \%$ at a higher $\mathrm{Cr}$ concentration of $25 \mathrm{mg} / \mathrm{L}$ to $83 \%$. Although the percentage removal decreased, the metal uptake per unit weight of the adsorbent $(\mathrm{mg} / \mathrm{g})$ increased.

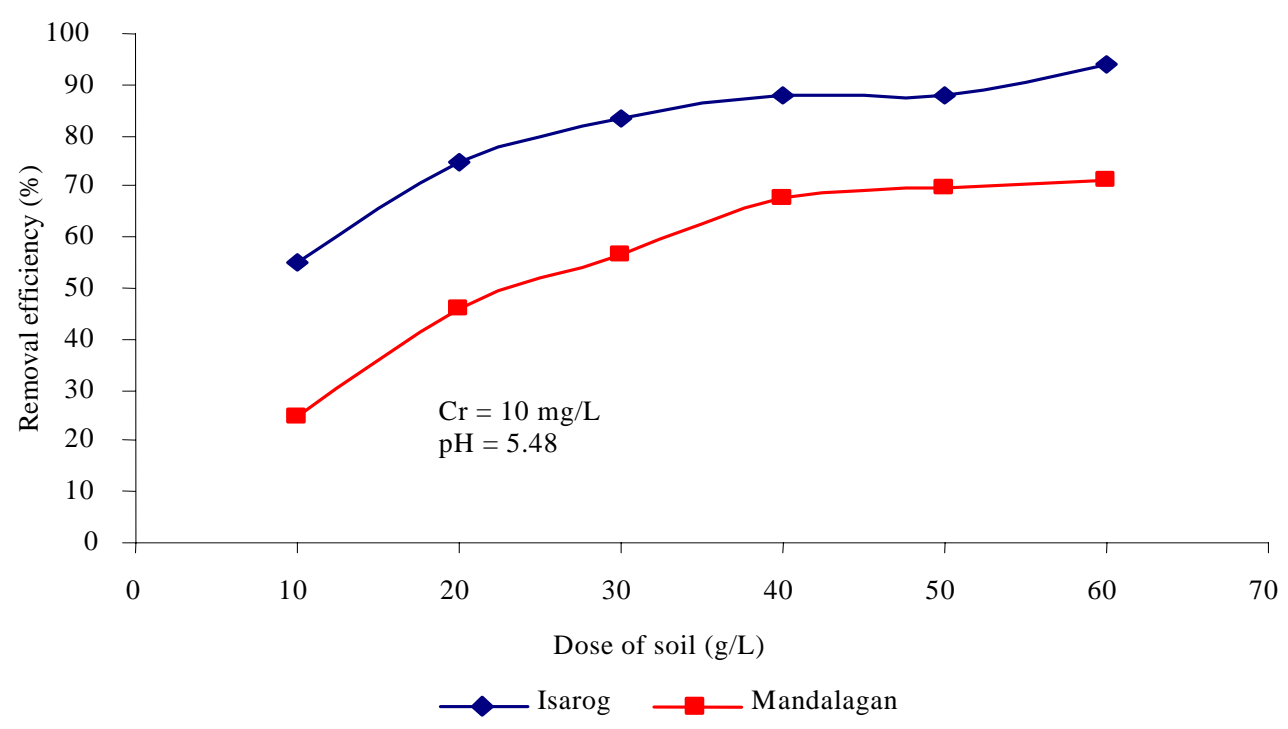

Fig. 1 Effect of the dose of adsorbent 


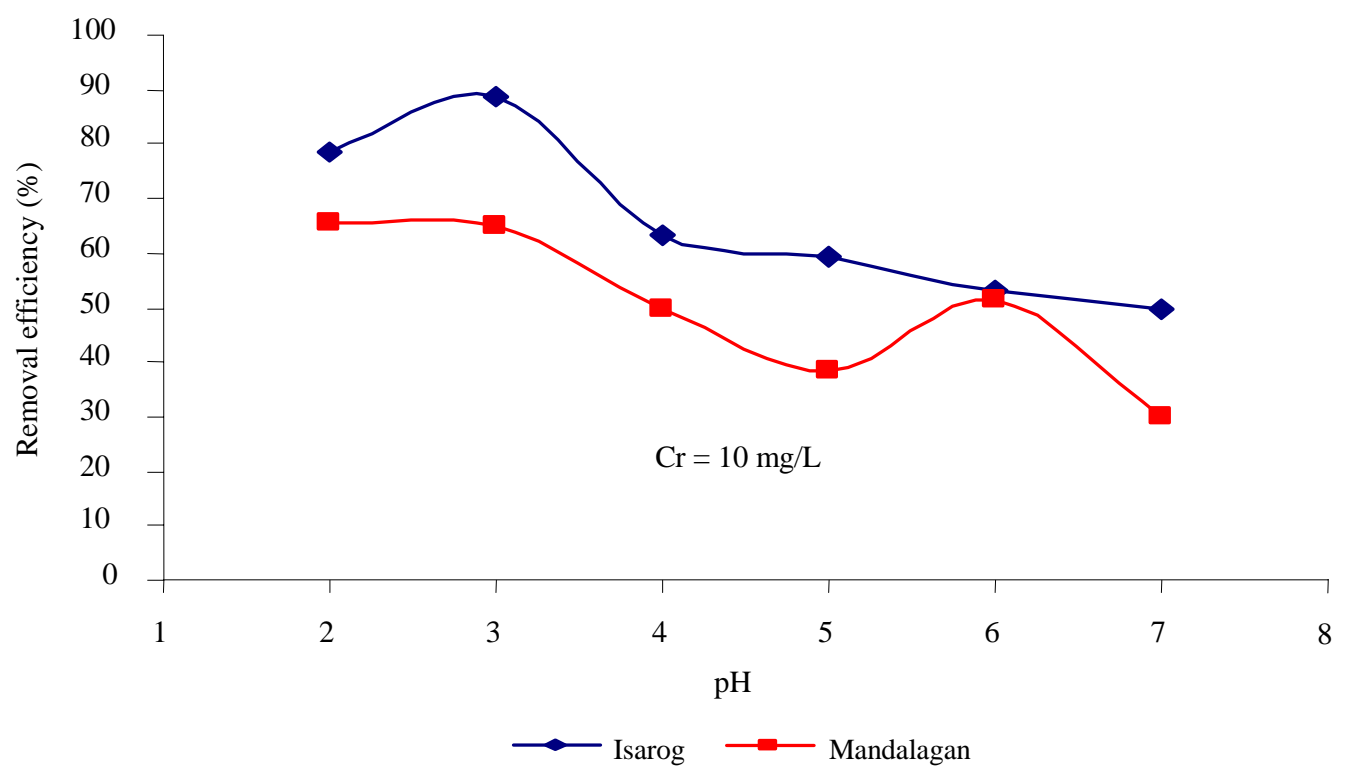

Fig. 2: Effect of the initial $\mathrm{pH}$ of the solution

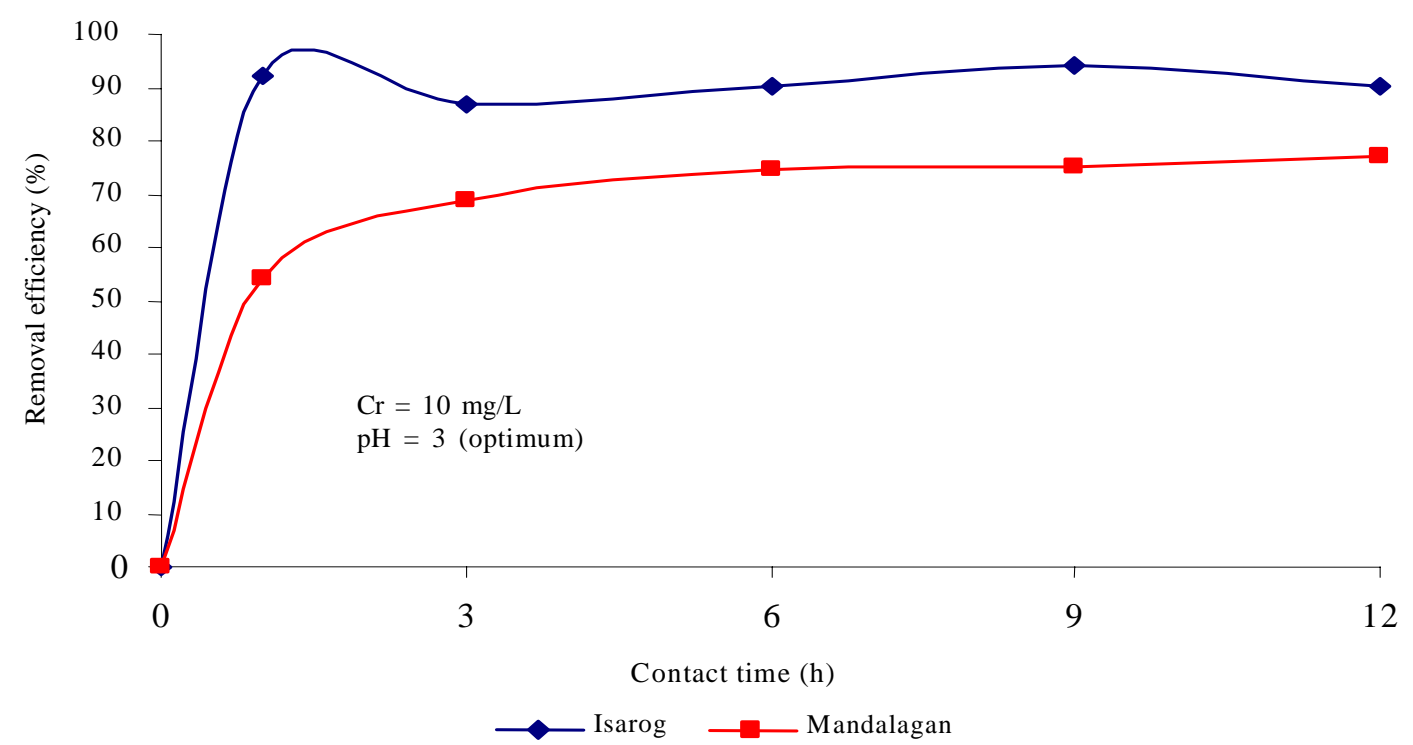

Fig. 3: Effect of contact time

\section{Effect of $p H$}

The $\mathrm{pH}$ of the solution is an important parameter that dictates the adsorption behavior of metal ions in aqueous systems. The $\mathrm{pH}$ does not only determine the speciation of metal ions in the solution but also determines the surface charge of the colloids in the soils. These charges vary based on the point of zero net charge (PZNC). The PZNC of Andisols has an important impact on its soil exchange properties. When the $\mathrm{pH}$ value is less than the PZNC, the variable charge sites develop a net positive charge and conversely, they have a net negative charge when $\mathrm{pH}$ value is greater than PZNC (Madeira et al., 2004). Due to its anionic character, $\mathrm{Cr}$ is favourably adsorbed at lower $\mathrm{pH}$ values. Hence, the effect of $\mathrm{pH}$ as shown in Figure 2 revealed that the maximum adsorption occurred at moderately acidic $\mathrm{pH}$ of 3 for the two soil samples. For the Isarog soil, the removal of $10 \mathrm{mg} / \mathrm{L} \mathrm{Cr}$ using $20 \mathrm{~g} / \mathrm{L}$ of soil increased from 78.3 to $88.9 \%$ with an increase 
of $\mathrm{pH}$ from 2 to 3 and decreased gradually as the $\mathrm{pH}$ of the solution increased. The removal efficiency of Mandalagan soil however showed a very slight decrease from 65.8 to $65.2 \%$ from $\mathrm{pH} 2$ to 3 and decreased gradually to $38.3 \%$ as the $\mathrm{pH}$ increased at the same conditions and parameters. It also showed an increase from 38.3 to $51.4 \%$ from $\mathrm{pH} 5$ to 6 and a decrease thereafter. Similar behaviour of Isarog soil was observed by the study of Singh, et al., (2005) using rice bran which also shows an increase of adsorption from $\mathrm{pH} 1.4$ to 2 before it decreased gradually as the $\mathrm{pH}$ increases. This sorption edge whereby adsorption increases rapidly over a relatively narrow $\mathrm{pH}$ range, is usually assumed to be the result of both variations in the surface charge and shift in solution ionic species (Harter, et al., 2001). It can be explained also on the basis of the nature of adsorbent used that contain several metal oxides. These oxides, when mixed up with adsorbate solution undergo surface hydroxylation that ultimately gives a positively or negatively charged surface as a result of subsequent acid-base dissociation (Singh, et al., 2005). Moreover, the two forms of $\mathrm{pH}$ dependent hexavalent chromium are $\mathrm{Cr}_{2} \mathrm{O}_{7}^{2-}$ and $\mathrm{CrO}_{4}^{2-}$ in which the former predominates at $\mathrm{pH}$ below 6 (Potgeiter et al., 2005). Thus, it is evident that VAS adsorbs more effectively the $\mathrm{Cr}_{2} \mathrm{O}^{2-}$ form of $\mathrm{Cr}$.

\section{Effect of contact time}

The adsorption behaviour of Cr by VAS in relation to the effect of contact time was carried out by varying the equilibrium time from 1 to $12 \mathrm{~h}$ at a $\mathrm{Cr}$ concentration of $10 \mathrm{mg} / \mathrm{L}$, a dose of adsorbent of $20 \mathrm{~g} / \mathrm{L}$ and at optimum $\mathrm{pH}$ of 3 for the two soils. The results showed that a one-hour equilibrium time for the Isarog soil is enough to remove more than $90 \%$ of $\mathrm{Cr}$ indicating that the reaction is fast and the adsorption sites are well exposed as compared to Mandalagan soils where the equilibrium was reached in $3 \mathrm{~h}$. Not much further increase in removal efficiency was observed with time for Isarog soil (Fig. 3). For Mandalagan soil, maximum removal observed was $70 \%$ after $6 \mathrm{~h}$ of contact time. The higher removal efficiency and shorter equilibrium time observed for the Isarog soil as compared to Mandalagan soil can be attributed to its higher clay content, porosity and lower bulk density, which supports that the Isarog soil has fine particles (high surface area) and more amorphous soil minerals leading to higher removal efficiency. Fig. 3 shows the effect of contact time on the removal of $\mathrm{Cr}$ by the two VAS.

\section{Chromium adsorption by VAS}

The adsorption of anions by Andisols is caused by chemisorption on 'active' $\mathrm{Al}$ and Fe occurring in various forms such as allophane, organometallic complexes and ferrihydrite (Wada, 1989). The results of FTIR analysis revealed that the characteristics of IR bands with regards to the binding of dichromate ions in the soil were reflected in the shift of the bands of silica and carbonates functional groups after the adsorption of $\mathrm{Cr}$ on the adsorbent. Similar results was observed by Singh, et al., (2005) in which the binding of Cr on to rice bran was coupled with the shift of IR bands of dichromate ions. On the other hand, after treatment, an increase in the $\mathrm{pH}$ of the solution by at least 1.2 $\mathrm{pH}$ units was recorded regardless of the amount of adsorbent. This can be explained by the similar findings of Zevenbergen et al., (1998) for $\mathrm{F}$ adsorption by Andisol in Kenya in which the noted increase in $\mathrm{pH}$ is a result of $\mathrm{F}$ adsorption accompanied by stoichiometric release of $\mathrm{OH}^{-}$and $\mathrm{pH}$ buffering by the soil components.

\section{Adsorption isotherm studies}

Analysis of the isotherm data is necessary in order to develop an equation that can accurately represent the results and could be used for design purposes (Mahvi, et al., 2004). The data obtained from the adsorption isotherm studies were fitted to the Langmuir and Freundlich isotherms. The Langmuir model, as shown in Eq. (1), assumes that the uptake of metal ions occurs on a homogenous surface by monolayer adsorption without any interaction between the adsorbed ions and the energy of adsorption is the same for all surface sites. The a and $\mathrm{b}$ are Langmuir constants which correspond to the maximum adsorption capacity ( $\mathrm{mg} / \mathrm{g}$ ) of adsorbent and energy of adsorption, respectively. The parameter $\mathrm{C}_{\mathrm{e}}$ corresponds to the remaining metal ion concentration in the solution and Qe refers to the amount of metal ions sorbed per unit weight of adsorbent.

$Q_{e}=\frac{a b C_{e}}{1+a C_{e}}$ 

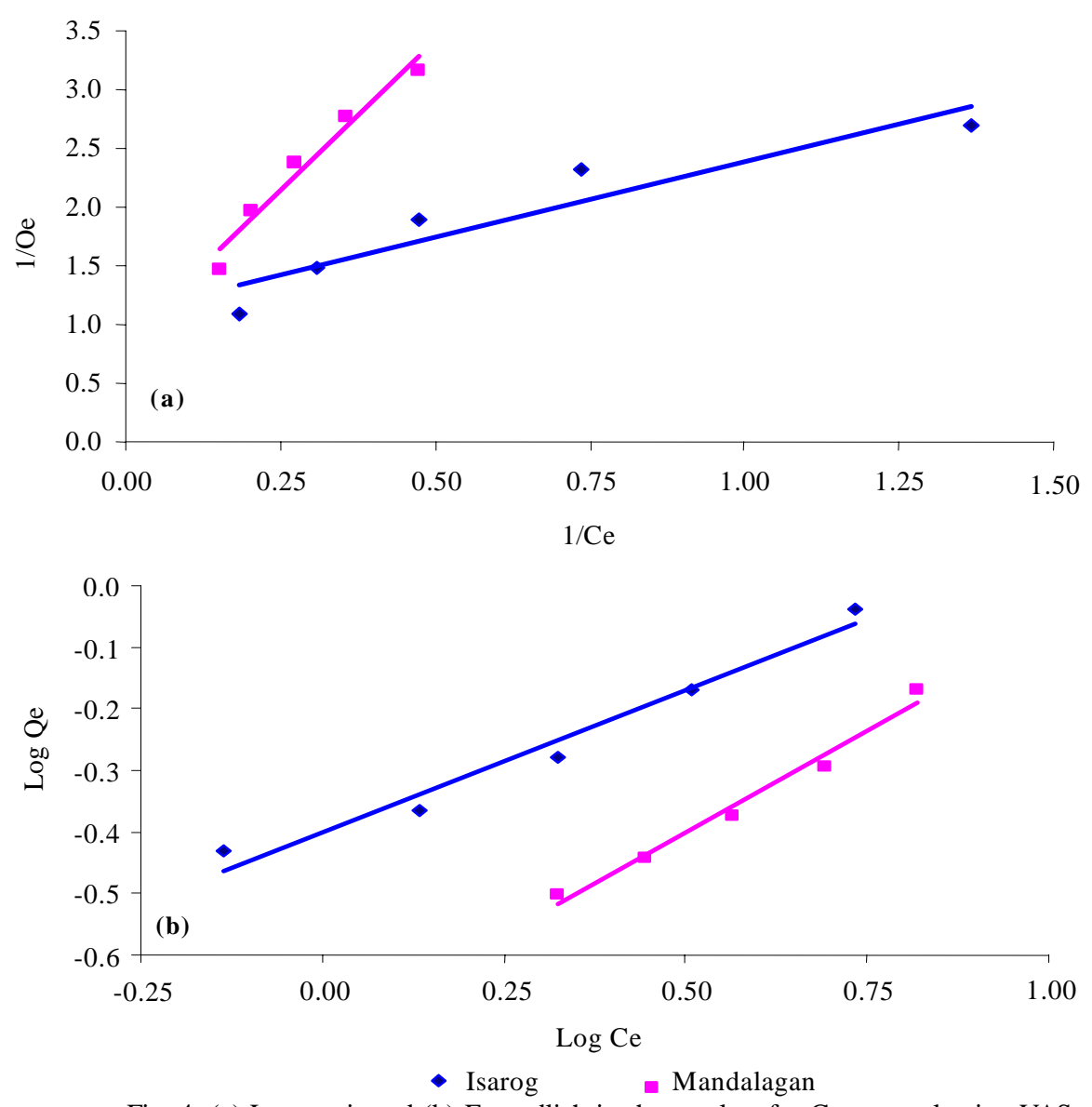

Table 2: Parameters of Freundlich and Langmuir Isotherm models

\begin{tabular}{lllllll}
\hline & \multicolumn{4}{c}{ Langmuir Constants } & \multicolumn{1}{c}{ Freundlich constants } \\
\hline & $\mathrm{a}(\mathrm{mg} / \mathrm{g})$ & $\mathrm{b}(\mathrm{L} / \mathrm{mg})$ & $\mathrm{R}^{2}$ & $\mathrm{~K}$ & $\mathrm{n}$ & $\mathrm{R}^{2}$ \\
Isarog & 0.864 & 0.903 & 0.8821 & 0.398 & 2.178 & 0.9693 \\
Mandalagan & 0.171 & 1.153 & 0.9627 & 0.186 & 1.519 & 0.9788 \\
\hline
\end{tabular}

The Freundlich isotherm on the other hand as shown in Eq. (2) assumes that the uptake of metal ions occur on a heterogeneous surface by multi-layer adsorption and the amount of adsorbate adsorbed increases with increasing concentration. The $K_{d}$ and $\mathrm{n}$ are the constants of the Freundlich isotherm that correspond to the adsorption capacity and intensity, respectively. The parameter $\mathrm{C}_{\mathrm{e}}$ corresponds to the remaining concentration of the adsorbate in the solution and $Q_{e}$ is the amount adsorbed at equilibrium (Reynolds, et al., 1996).
The constants of the two isotherm equations can be computed from the intercept and slope of the linearized plot of the experimental:

$$
Q_{e}=K_{d} C_{e}^{\frac{1}{n}}
$$

The isotherm constants were calculated from the slope and intercept of Fig. 4 a and $4 \mathrm{~b}$ and are presented in Table 2. The values of correlation coefficient $\mathrm{R}^{2}$ obtained were higher in the Freundlich isotherm than in the Langmuir isotherm for Isarog soil which indicates that the adsorption process is well represented by the Freundlich equation. This may confirm the heterogeneous nature of the VAS surface and is in agreement with the similar findings of Esmaili et al., (2003) using VAS from Kerman province, Iran, for $\mathrm{Pb}$ and $\mathrm{Zn}$ removal. In contrast, the adsorption process of Mandalagan soil can be represented both in Langmuir and Freundlich isotherms. 
It can be seen from the figures that the VAS from Isarog is a more efficient adsorbent than Mandalagan to remove $\mathrm{Cr}$ from synthetic wastewater. Moreover, the values of $n$ of the Freundlich isotherm constants between 1 to 10 indicate an effective adsorption (Potgeiter, et al., 2005). The fractional value of $1 / \mathrm{n}$ between 0 to 1 signifies that the surface of the adsorbent is heterogeneous in nature while the higher value of $\mathrm{K}$ represents an easy uptake of adsorbate from the solution (Mahvi, et al., 2004).

\section{DISCUSSION AND CONCLUSION}

This study showed that volcanic ash soil or Andisols which are dominated by amorphous soil minerals such as in Mt. Isarog, could be used as an effective adsorbent for the removal of $\mathrm{Cr}$ from contaminated wastewater. These natural materials are relatively abundant in those countries with many active volcanoes and can be used as an alternative to commercially available adsorbents for $\mathrm{Cr}$. The soil from Mt. Isarog is found to be more effective than in Mt. Mandalagan since the former may contain more active soil minerals that can bind the Cr effectively at optimum conditions. The sorption capacity was highly dependent on the $\mathrm{pH}$ of the solution. The maximum removal efficiency of Isarog without changing the $\mathrm{pH}$ of the synthetic wastewater reached $93 \%$ for $10 \mathrm{mg} / \mathrm{L} \mathrm{Cr}$ at a dose of $60 \mathrm{~g} / \mathrm{L}$ of soil. An almost equal amount (89\%) of removal was observed at optimum $\mathrm{pH}$ of 3 but the dose was reduced by one-third ( $20 \mathrm{~g} / \mathrm{L})$ for the same $\mathrm{Cr}$ concentration of $10 \mathrm{mg} / \mathrm{L}$. The Mandalagan soil on the other hand only reached $71 \%$ for a dose of $60 \mathrm{~g} / \mathrm{L}$ and $65 \%$ at optimum $\mathrm{pH}$, respectively, at the same conditions and parameters. The percentage removal efficiency of the VAS decreases as the $\mathrm{pH}$ of the solution increases. The removal of hexavalent chromium was rapid and one hour equilibrating time was enough for Isarog to reach maximum removal efficiency while that of Mandalagan is $3 \mathrm{~h}$. An increase in initial metal concentration also decreased the percentage of adsorption of the soils but increased the metal uptake per unit weight of adsorbent. The fitness of the adsorption data of the Isarog soil into the Freundlich isotherm confirmed its heterogeneous nature while the Mandalagan soil can be represented by both Freundlich and Langmuir isotherms.

\section{ACKNOWLEDGEMENTS}

This study was conducted as part the scholarship grant from the Joint Graduate School of Energy and Environment at King Mongkut's University of Technology Thonburi. The authors are also grateful to Dr. Lorena F. Hernandez of the Camarines Sur State College of Agriculture, Mr. Dante S. Margate of the Bureau of Soils and Water Management and Mr. Argie Gavilangoso for their assistance in collecting the soil samples and in the analysis.

\section{REFERENCES}

Esmaili, A., Nasseri, S., Mahvi, A., Atash-Dehghan, R., (2003). Adsorption of lead and zinc ions from aqueous solution by volcanic ash soil. Mining and Environment III Conference, Available online: http://www.x-cd.com/sudbury03/ prof41.html.

Harter, R., Naidu, R. (2001). An assessment of environmental and solution parameter impact on trace-metal sorption by soils. Soil Sci. Soc. Am. J., 65, 597-612.

Krishna, B.S., Murty, D.S.R., Jai Prakash, B.B., (2000). Thermodynamics of chromium (VI) anionic species sorption onto surfactant-modified montmorillonite clay. J. Coll. Inter. Sci., 229, 230-236.

Kurniawan, T., (2002) A research study on Cr (VI) removal from contaminated waste water using chemically low cost adsorbents and commercial activated carbon. Thesis EVMS-2002-01.

Madiera, M., Auxtero, E., Sousa, E, (2003). Cation and anion exchange properties of Andisols from the Azores, Portugal, as determined by the compulsive exchange and the ammonium acetate methods. Geoderma, 117, 225-241.

Mahvi, A.H., Maleki, A., Eslami, A, (2004). Potential of rice husk and rice husk ash for phenol removal in aqueous system. Am. J. Appl. Sci., 1 (4), 321-326.

Nanzyo, M., (2002). Unique properties of volcanic ash soils. Available online: http://www.airies.or.jp/publication/ger/pdf/ 06-2-11.pdf.

Okada, K., Nishimuta, K., Kameshima, Y., Nakajima, A., (2005). Effect on uptake of heavy metal ions by phosphate grafting of allophane. J. Coll. Inter. Sci., 286, 447-454.

Otsuka, H., Brioness, A., Daquiado, N., Evangelio, F., (1988). Characteristics and genesis of volcanic ash soils in the Philippines. Technical Bulletin of the Tropical Agriculture Research Center No. 24, Ministry of Agriculture, Forestry and Fisheries, Japan.

Perret, S., Dorel, M., (1999). Relationship between land use, fertility and Andisol behavior: examples from volcanic islands. Soil Use Manag., 15, 144-149.

Potgeiter, J., Potgeiter-Vermaak, S., Kalibatonga, P., (2005). Heavy metals removal from solution by palygorskite clay. Minerals Engineering, Article in Press.

Reynolds, T., Richard, P., (1996). Unit operations and processes in environmental engineering. PWS Publishing Company, USA.

Singh, K.K, Rastogi, R., Hasan, S.H., (2005). Removal of Cr (VI) from wastewater using rice bran. J. Coll. Inter. Sci.,, Article in Press 
Smith and Atkinson, (1976). Techniques in Pedology (Laboratory Analyses)

Stepniewska, Z., Bucior, K., Bennicilli, R., (2004) The effects of $\mathrm{MnO}_{2}$ on sorption and oxidation of Cr (III) by soils. Geoderma, 122, 291-296.

Stewart, M., Jardine, P., Barnett, M., Mehlhorn, T., Hyder, L., McKay, L., (2003) Influence of soil geochemical and physical properties on the sorption and bioaccessibiltiy of Chromium (III). J. Environ. Quality, 32, 129-137.

Ugolini, F., Dahlgren R., (2002). Soil Development in Volcanic Ash. Available online: http://www.airies.or.jp/publication/ger/ pdf/06-2-09.pdf,.
Violante, A., Pigna, M., (2002) Competitive sorption of arsenate and phosphate on different clay minerals and soils. Soil Sci. Soc. Am. J., 66, 1788-1796.

Wada, K., (1989). Allophane and imogolite: Minerals in Soil Environments. Soil Sci. Soc. Am. J., SSA Book Series, No. 1 Zevenbergen, C., Van Reeuwijik, L., Louws, R., Schuiling, R., (1996). A simple method for defluoridation of drinking water at village level by adsorption on ando soil in Kenya. Sci. Total Environ., 188, 225-232.

\section{AUTHOR (S) BIOSKETCHES}

Babel, S., M.Sc., Ph.D. is associate professor in environmental technology program at Sirindhorn International Institute of Technology, Thammasat University, Bangkok, Thailand. Email: sandhya@siit.tu.ac.th

Opiso, E.M., is graduate student and pursuing masters in environmental technology at Sirindhorn International Institute of Technology, Thammasat University, Bangkok, Thailand. Email: einstineop@gmail.com

This article should be referenced as follows:

Babel, S., Opiso, E.M., (2007). Removal of Cr from synthetic wastewater by sorption into volcanic ash soil. Int. J. Environ. Sci. Tech., 4 (1), 99-107. 